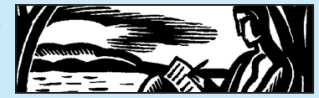

\title{
Printing a New Story: Self-representation, Disability, and Digital Fabrication
}

\author{
Ursula Hurley
}

The University of Salford, UK

\section{ABSTRACT}

This essay presents an account of an AHRC Connected Communities Innovation project which used creative writing techniques as a process for generating personally meaningful digitally-fabricated objects, probing the potential of making practices to catalyse cultural change with and for disabled people. This account explores the processes and products of experimental approaches to digital fabrication, speculating that they may be understood as a kind of poetic language, capable of generating counter-hegemonic narratives, which may be read as acts of self-representation. Digital fabrication's literal/metaphorical qualities are read through the lens of 'complex embodiment', proposing that this technology may be particularly suited to inclusive auto/biographical expression, empowering disabled people to print new stories for and about themselves.

Keywords: Digital fabrication; disability; complex embodiment; counter-hegemonic narratives; poetic practice

\section{INTRODUCTION}

Let's begin with the magic box:

This box can make anything that you can imagine.

Think it, and it will materialise inside the box.

What's in the box? 
Share with a partner. As you listen to your partner's account, think about the story behind the object. What is the need, desire or experience that prompted them to imagine their object?

(Ideation prompt, field work, 2015)

To many people, particularly those unfamiliar with the technology, a 3D printer can seem like a magic box. Entry-level machines are mainly hollow cubes, occupying two to three cubic feet on a table top. Once they are supplied with a design code, they appear to materialise objects out of thin air, transforming data into things. Within technical limitations, they can make anything we can think: 'the formerly fictional idea of such a "magic machine" has been turned into reality'. ${ }^{1}$ While we have not yet reached the realms of the Star Trek replicator, Bryan Nelson claims that fabrication technologies are developing towards such capabilities. ${ }^{2}$

The purpose of this enquiry is not to explore science fiction, but to consider 3D printing technologies as they currently exist, and how they might offer opportunities for self-representation to people who may be excluded from or discouraged by more conventional forms of auto/ biographical practice. My intention is to explore what Christopher Johnson posits as the 'revealing function' of new technologies such as digital fabrication: 'that is, how they permit modes of experience, conceptualisation and representation hitherto unimagined'. ${ }^{3}$ Once I have set out how digital fabrication might have the potential to materialise hidden aspects of lived experience, establishing its 'revealing function', I will then present some examples and tentative conclusions from the 'In the Making' project, suggesting how disabled people deployed the technology to situate themselves as authors of their own stories. 'In the Making' is an AHRC Connected Communities Innovation project (AH/M006026/1), which set out to explore the potential of digital fabrication practices to catalyse cultural change with and for disabled people. The project was co-constructed with people from the Greater Manchester area of the UK, who identified as disabled. ${ }^{4}$ The project team introduced digital fabrication equipment and expert facilitators into community settings and invited people to explore the technology. People could make whatever they wanted-the only boundaries were imposed by technical limitation. However, the emphasis throughout was not on the production of assistive aids (which pose the disabled body as a 'lack' which requires a prosthetic fix), but on the opening up of a 'fabulous fab lab' in which people could experiment with making as an assertion of agency. 
To allow the project's outputs to be read through a literary/critical lens, I will outline some conceptual intersections of digital fabrication, and disruptive cultural narratives. Having set out this critical context, I will then suggest how the intersection with disability is particularly productive. The way into such readings is not through the technology itself but via the language and the literary devices that people use to describe what the technology might reveal. As we found in our fieldwork, the concept of the box is particularly resonant. For Neil Gershenfeld, inventor of the Fab Lab movement, ${ }^{5}$ and a leading commentator on 'making' cultures, the revolutionary potential of digital fabrication technologies will be realised 'quite literally out of the box, in making the box'. ${ }^{6}$

To make sense of Gershenfeld's phrase is to hover between material and conceptual states, just as 3D printers invite us to do. Such machines exceed copyright and intellectual property laws, challenging traditional models of production. A design file can be posted online for anyone to download; a copyrighted object can be scanned and reproduced locally. As Lyndsey Gilpin points out in an article for techrepublic.com, '3D printers offer the ability to produce a wide range of objects that cannot be controlled yet'. ${ }^{7}$ Publicly accessible maker spaces and the relative affordability of home-user equipment have brought us to a point where, 'For the first time in history, laypeople can participate in the product design and manufacturing process by directly interacting with the underlying hardware and software'. ${ }^{8}$

Beyond the more obvious challenges to legal, economic and ethical considerations, digital fabrication poses subtler, more profound and potentially disturbing questions about what it means to be human. Matthew Causey, for example, articulates a 'contemporary theory of subject construction in mediatized culture'. ${ }^{9}$ The first consideration in such a culture is, according to Causey, that 'the material body and its subjectivity are extended, challenged and reconfigured through technology.' ${ }^{10}$ This problematising of the material body is demonstrated in the processes of digital fabrication. A handheld 3D scanner can quickly capture the digital information required to render a body in virtual form. During the 'In the Making' project, expert facilitators demonstrated the principles of 3D printing by supporting participants to make '3D selfies' of each other. To the facilitators this was a simple process, in which the scan was uploaded into 3D modelling software. To the subject of the scan (and I include my own experience I this account), an odd and potentially destabilising experience unfolds, in which an encounter with a highly detailed virtual self occurs by looking into a computer screen. An excerpt from my fieldnotes articulates the strangeness of the experience more fully: 
They [expert facilitators] put a chair in the centre of the room and we form an expectant circle.

'Right, who wants a 3D selfie?'

People seem puzzled by this until he explains that it's just like taking a selfie on your phone, but it'll come out of the printer instead. He takes a tiny, bronze-coloured bust of himself from his kit and passes it around.

'Does it hurt?' someone asks.

'No,' he laughs, 'but you've got to keep still.'

With some encouragement, an older man volunteers.

The Fab Lab has brought an adapted movement sensor from an Xbox Kinect, lashed to a broom handle. It's so simple and effective that after a few demos, one participant is able to scan another. A young woman with an autistic spectrum condition gets up from her crouch in the corner and becomes fully engaged. She passes slowly around the subject, repeating the circular movement, wielding the hacked scanner like a sacred staff, as the software gathers and collates the data. One of the facilitators crawls behind her, disentangling the wire connecting the sensor to the laptop, which kinks as it circles.

As well as watching the external action of this apparently ritualistic scan, we can also see the virtual image building on the laptop screen. The geography of the room is recognizable, but it seems to have gained in texture, as have the picture frames on the wall which now appear to be growing on it like lesions. Everything seems furry or fleshy, the slight lack of precision rendering it organic, disconcerting in contrast with the physical reality visible beyond the screen. The subject of the selfie sits mid-screen, as though emerging out of primordial mud. The rest of us are half-captured, the backs of our heads missing, as though darkness were erupting from our skulls. It reminds me of the scenes in Lord of the Rings where Frodo slips the ring on to his finger and everything becomes dark, matter streams and uncoils like smoke, distorted. We are watching ourselves forming in this virtual space, looking at each other 'out here' and simultaneously at our representations 'in there'. The small tea things on the serving hatch appear well rendered but the abyss behind them seems a portal to another world. I know that it is just a matter of data capture, that where people and things seem bizarrely distorted or missing, it is simply that the sensor has not detected their form completely. Perhaps it is just the unfamiliarity of the process, but it feels weird, despite my rational explanations to myself. The quality of the attention in the room is concentrated, absorbed. Everybody is absolutely engrossed. What's particularly notable is that people with attention deficit conditions, who have been volatile and unpredictable all day, are equally still and quiet, watching intently.

The image appears still to be fragmented, unfinished, but the experts declare the data capture complete. They highlight the subject of the selfie, whose image (still, to me, alarmingly amorphous-there seems to be blob-like distortion over his face) is now highlighted in red and green in the top right corner of the laptop screen (see Figure 1).

The experts tap away at the laptop keys, preparing the scan so that it becomes intelligible to the printer software. To them it seems easy, basic. To me it is technical and mysterious. I can work out the principles which must underpin the process, but I have no handle 


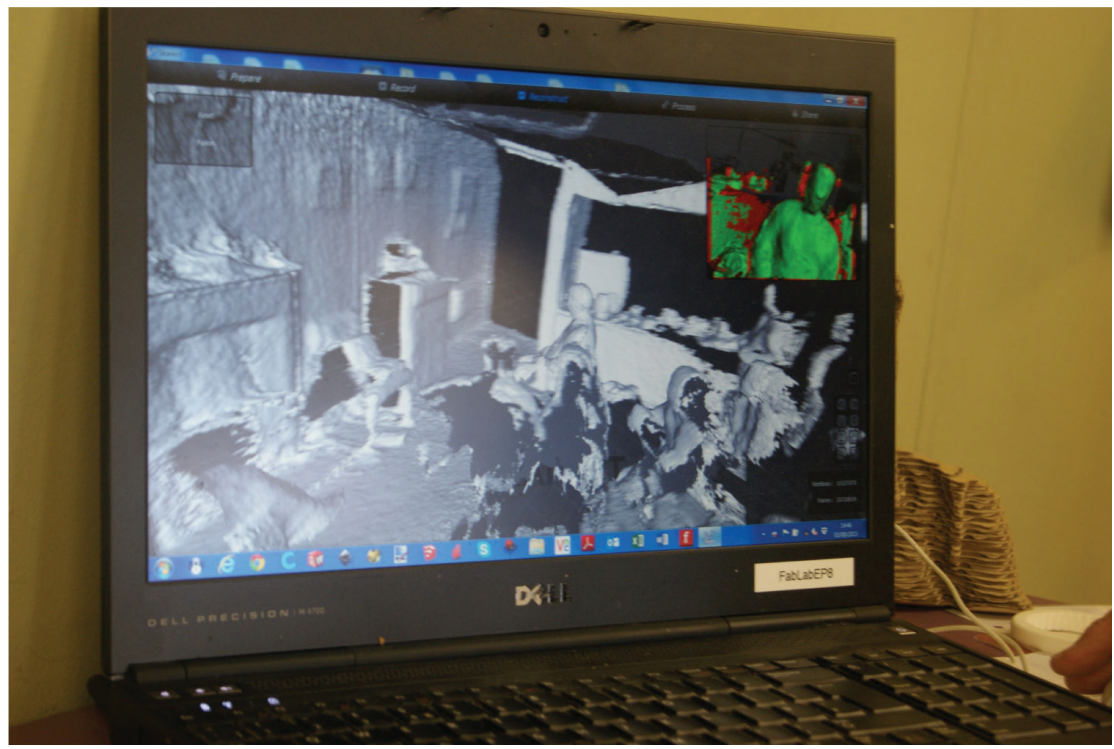

Figure 1. The scan that will form the basis of a 3D selfie appears blurrily on the laptop screen.

on the specifics. I ask if they can talk us through what's going on, but either they can't come down to my level of unknowing, or the language and the concepts aren't available because their commentary is superficial, and I still don't understand the actuality, so that I feel like someone who can't read Latin witnessing alchemists at work. There seems to be a process of iteration involving several different computer programmes. Scanner software refines and builds the scan into a sharper three-dimensional image. This has an extraordinary level of detail, including the logo on the subject's sweatshirt. It seems impossible that this clarity should emerge from the oddly woolly image that we first saw on the laptop screen. Another programme translates the detailed full-colour image into a shape that the printer can 'slice' into topographical layers. The image has now become a yellow statue. The only surface detail is topographical. Anything two-dimensional, like a logo, has been lost but the subject's glasses appear to have been preserved. The arm of his glasses along the side of his face is clear; clearer than it has been in previous iterations. There are losses and gains in this process. The folds in the fabric of his sweatshirt are beautifully rendered. The elbows have been sliced off, in the style of the Venus de Milo and the chequered background suggests a chess piece. In Figure 2, the laptop shows us both versions of the image, side by side.

The subject of the selfie peers closely at both on-screen versions of himself. There is a lot of fiddling with SD cards and then the subject is asked what colour he would like. He selects red and there is more fiddling while the printer filament is changed. But people 


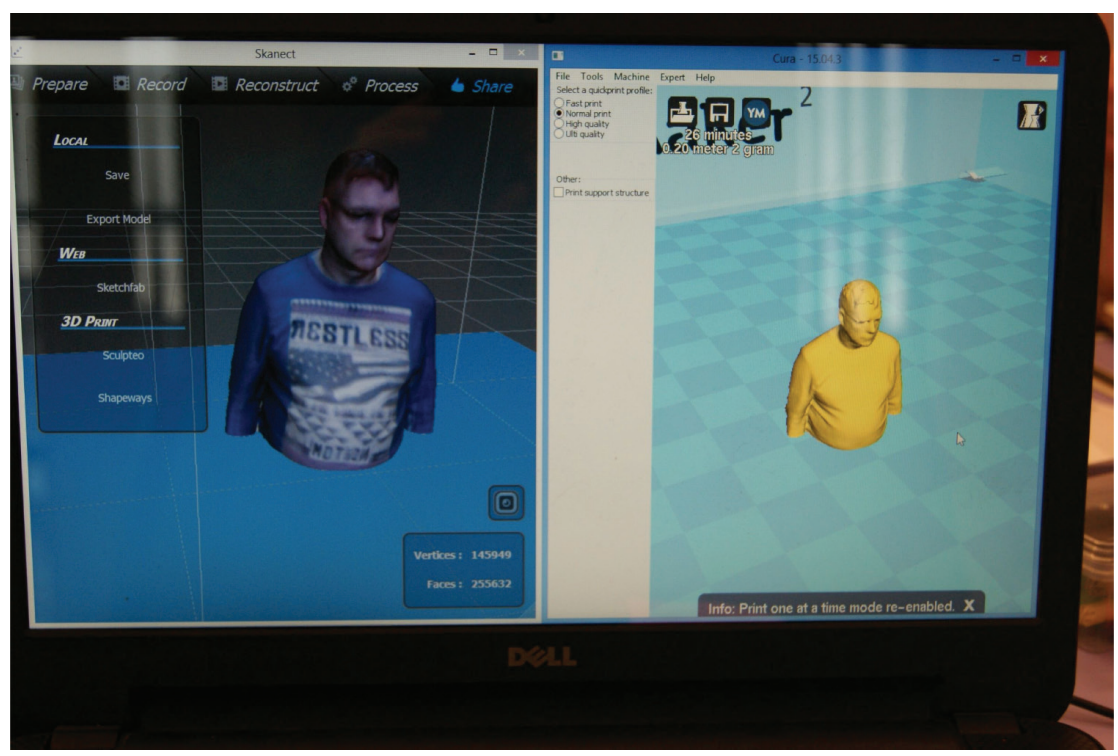

Figure 2. The virtual iterations in the 3D selfie process.

remain curiously attentive. They know there will be a pay-off. Suddenly the printer is alive, the build plate rises with a loud metallic whoosh and the print head begins to cast off with a thread of melted red plastic. Our experts liken the printer to a fancy microwave oven, as the digital display tells us how long the print will take to 'cook'. The problem now is getting people to keep still and refrain from touching the machine. Vibrations or drafts can lead to prints aborting, producing nothing more than a ball of 3D scribble. But our participants appear transfixed. The subject of the selfie appoints himself lead guard for the machine and won't allow anyone too near. The display indicates about 30 minutes print time, and he sustains this attention consistently throughout. We offer tea and biscuits at the other end of the room, trying to draw people and their vibrations away, but most stay and watch as the miniature version of the selfie materialises as a little red statue. Figure 3 shows the 3D selfie emerging.

There are no glitches, the print works first time and, once the plastic has cooled, the selfie subject reaches into the printer and removes his $3 D$ image. Beaming, he shows it to everybody. His carer states that she has never seen him sustain such engagement, nor such interaction with others. The atmosphere in the room has shifted. Re-energised, people talk more readily, as though we have been through something special together. Some participants chatter excitedly about what they have just witnessed. A young woman who was notably withdrawn and reluctant to interact is now laughing and cracking jokes. 'It's magic, that, innit?' she says, and it's not clear whether she means 'magic' in its colloquial sense of 'good' or 'particularly enjoyable', or whether she also 


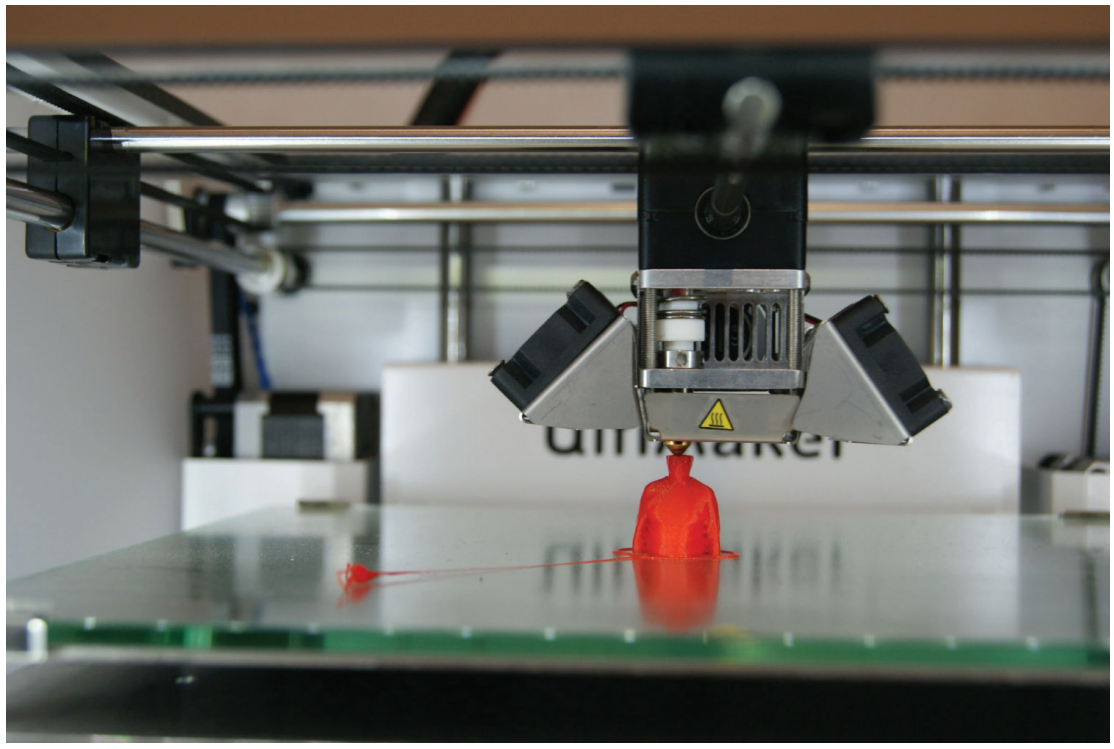

Figure 3. The selfie materialises on the print bed.

means to include the more traditional sense of something achieved by sleight of hand or even supernatural means. Others crowd around the printer, looking quizzically at the brightly lit cube, asking the experts to explain how it works.

Finally, the caretaker comes to tell us that he is locking up for the night. The experts put away their wires and laptops. The subject of the selfie strides out into the autumn evening, his three-dimensional image held aloft like a trophy.

Field notes, Salford, UK

September 2015

This account summarises the changes in state involved in a 3D selfie, where the physical body becomes a virtual body, before emerging once more as a physical artefact. The dimensions of the selfie are restricted only by the capacity of the particular printer involved. The subject of the '3D selfie' watches their virtual self materialise on the print bed, becoming present out of thin air. It may be a realistic copy of their real-life embodiment or, rather like applying a filter or effect to a two-dimensional photograph, the virtual body can be endlessly modified, manipulated and distributed across the internet. The self, and the world around it are re-encountered on a different plane of possibility, offering opportunities for and challenges to practices of self-representation. 
While this process may initially be destabilising for the subject of the 3D scan, it is also loaded with the potential for a performance of self which turns outward, to engage, challenge or provoke the spectator, prompting 'an open-minded exchange of perspectives resulting in "reciprocal illumination" for everyone who takes part'. ${ }^{11}$ The work of Teresa Bruś on the photographic selfie offers some transferable insights to the threedimensional selfie. Just like a producer of two-dimensional self-images, and illustrated in the above field notes, the maker of a three-dimensional self-image "participates in an intersubjective space where showing, sharing and visual conversing create a promising arena for self-enactment and extension of subjectivity'. ${ }^{12}$ Demonstrating the promise of the inclusive FabLab as an arena for exploring and extending self-enactment, one woman who contributed to our project chose to 'redesign' herself with extravagant angel wings. A man transformed himself into a gender-fluid octopus. Others recast themselves as cartoon characters or superhero avatars. Some of these self-concepts could be actualised immediately as prints, others remained at the conceptual stage because of the technical limitations of our equipment. Figures $4-7$ offer a representative sample:

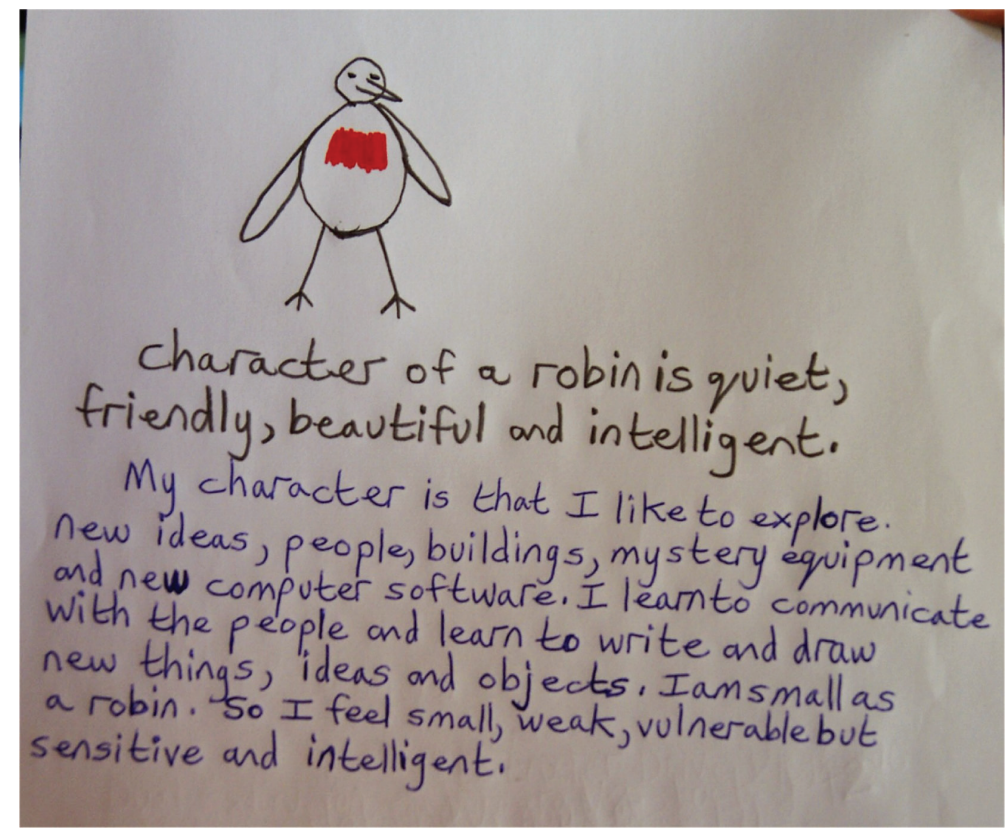

Figure 4. A participant's idea for a 'robin' avatar, and his reasons for identifying with this creature. 


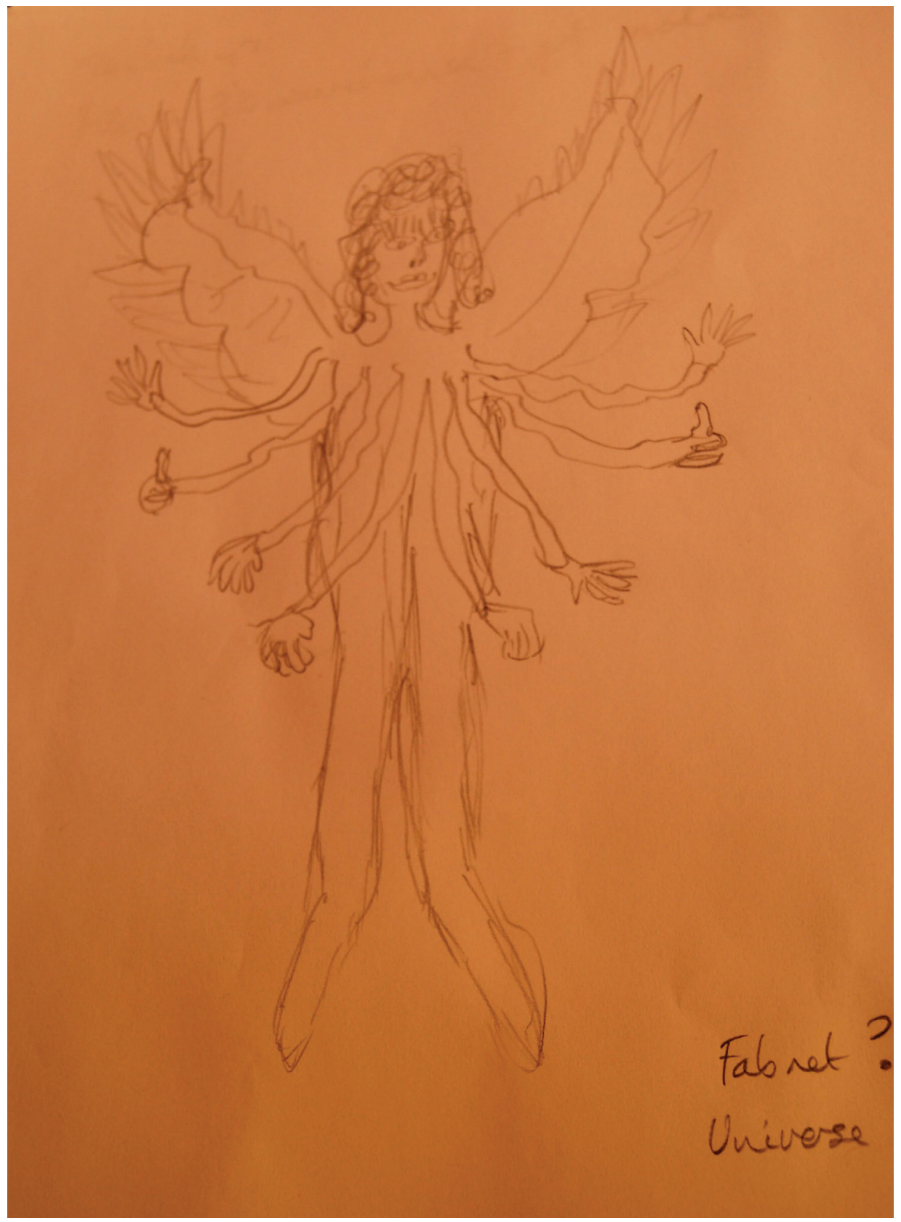

Figure 5. A multi-limbed winged 'angel' concept drawing for a 3D-printed avatar. The feathers, hair and hands proved challenging to realise on our equipment.

Much of the above self-representational activity could have been achieved by creative facilitation alone, and it could be argued that 3D printing equipment was not essential to bringing it about. However, the affordances of digital fabrication technology make it uniquely placed to widen participation in auto/biographical practices. My fieldnotes document the powerful allure of the 3D printing process for people who may not usually wish or be able to participate in conventional acts of selfrepresentation. In a digital fabrication workshop, self-representation 


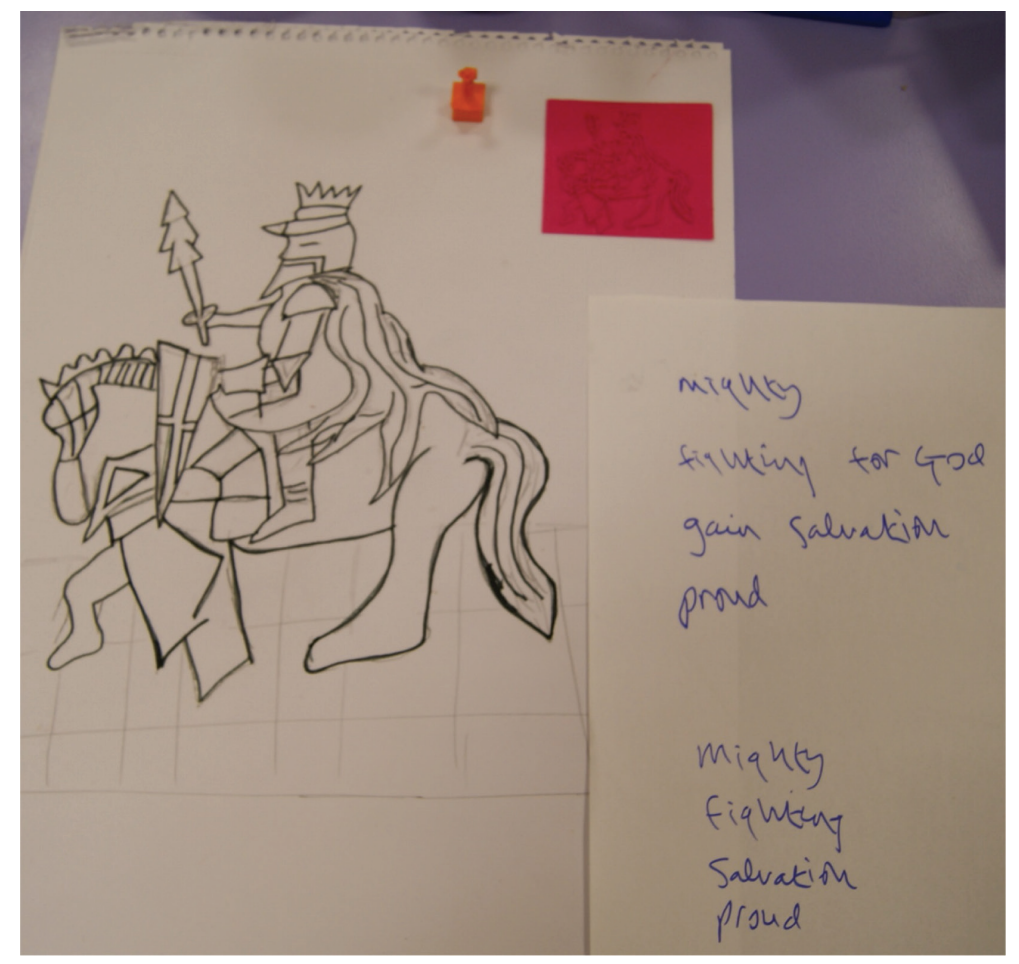

Figure 6. Initial text and scale drawing for a 'mighty knight' avatar, representing for its maker strength, pride and salvation (the hand-written notes were dictated to a facilitator). A 3D printed chess figure, and a relief print of the scanned drawing are just visible in the top right-hand corner.

becomes part of a process which results in the materialisation of a unique object; it is not the end goal. Participants are therefore relieved of the expectation to produce a suitably significant and appropriate auto/biographical outcome. 3D printers make the process of materialisation, and the relationship between mental, virtual, and physical states engagingly clear, offering the potential for prints to be "produced and used in individual ways as [...] practices of identification, recognition and inscription'. ${ }^{13}$ While currently much less prevalent as a cultural phenomenon, 3D-printed self-representations (like 2D photographic selfies) constitute 'distinctive technical bases' for 'an enlarging practice of assertion and performance of lived existence'. ${ }^{14}$ While many art forms offer the same general ability to combine conceptual and material elements, the distinctive qualities of digital fabrication are beginning to receive critical 


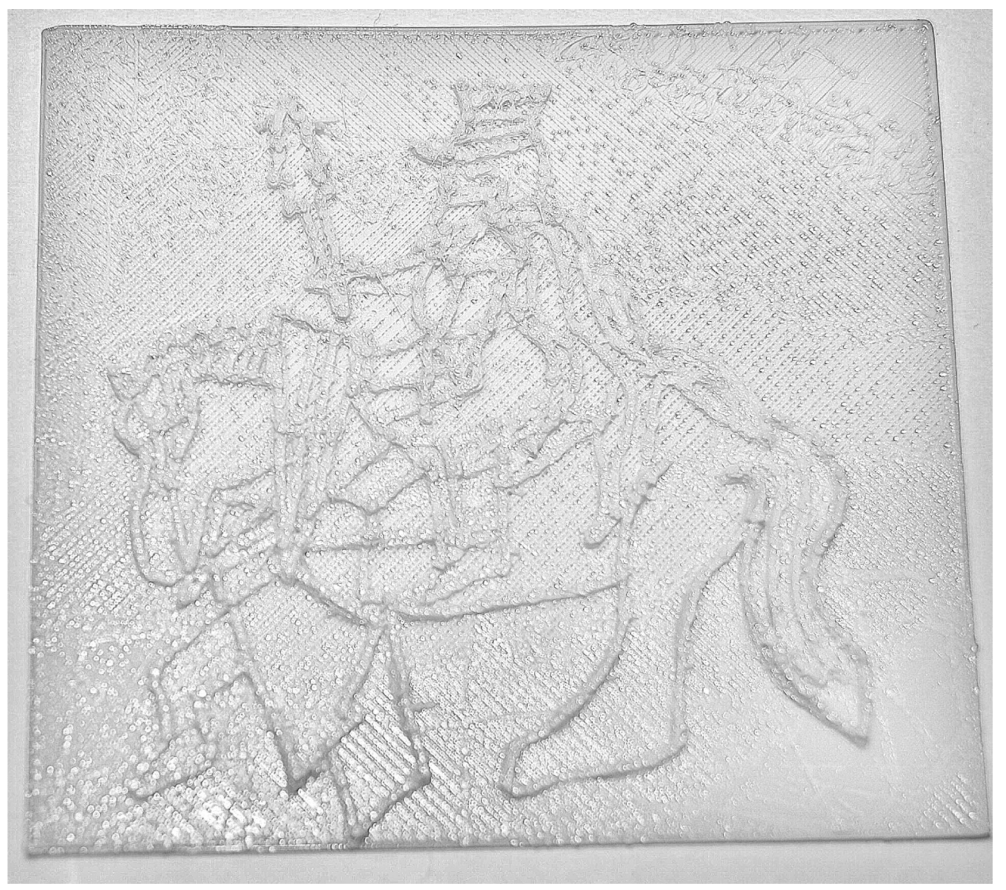

Figure 7. Close-up of the relief 3D print of the original 'Knight' drawing, designed to work like a medieval brass rubbing.

attention. Writing about the Brass Art Collective's recent 'Gestured' project, Rowan Bailey describes 3D printing's 'special kind of materialism', in which 'preoccupations with the transformation of matter [...] point us towards alternative histories or stories'. ${ }^{15}$ In the encounter with such meaningful 3D-printed objects, the viewer must 'learn how to read for insights in the materials', as the beholder is also 'transformed by being carried from one state to another'. ${ }^{\prime}$

As this essay unfolds, I will attempt to support more specifically the claims made here, by detailed reference to the processes and products generated by our project. The destabilising and transformational effects outlined above will be considered as acts of self-representation. To facilitate these ambitions, I turn first to the concept of 'complex embodiment', as articulated by Disability Studies scholars. Liat Ben-Moshe believes that understanding disability as embodied identity helps to overcome the respective limitations of medical and social models of disability. The medical model, in its framing of disability as a set of defects to be 
remedied, and the social model, in its emphasis on disabling social structures, both lead to 'over-representation of ... visible disabilities', with the consequence that many experiences of disability remain hidden. ${ }^{17} \mathrm{Com}$ plex embodiment is a more productive alternative because it "combines social and corporeal factors' in ways that make explicit 'the myriad disabilities and impairments that could and should be analyzed.... ${ }^{18}$ BenMoshe extends this claim by explaining that:

while identities are socially constructed, they are nevertheless meaningful and real precisely because they are complexly embodied. The complex embodiment apparent in disability is an especially strong example to contemplate because the disabled body compels one to give concrete form to the theory of social construction and to take its metaphors literally. ${ }^{19}$

The virtual/material transformations inherent in digital fabrication processes, and their ability to embody previously invisible or intangible aspects of experience, resonate strongly with Ben-Moshe's articulation of complex embodiment, and may serve to perform the concept in concrete terms. Giving material expression to the experience of social constructions is an aspiration which 3D printers can support, while making visible hitherto hidden experiences of disability is part of what Christopher Johnson posits as the 'revealing function' of new technology. ${ }^{20}$ Strongest of all these resonances, however, is the call to 'take its metaphors literally'. This phrase brings us back to Gershenfeld's figurative/literal prophecy that we can only 'get out of the box by literally making the box'. ${ }^{21}$ For BenMoshe, however, it is not the new technology which compels us to take metaphors literally but rather the disabled body.

Given that disability and digital fabrication seem to align so closely in critical accounts of their qualities, it would be productive to facilitate a dialogue between them. The 'In the Making' project hypothesised that we could engage digital fabrication technologies as a way of thinking 'out of the box' about representations of disability, and of making new frames which provide a counter-narrative to what Timothy Barrett identifies as 'the cultural construction of experiences of impairment as unendingly tragic and/or alien'. ${ }^{22}$ Gershenfeld ('How to Make') emphasises the ability of digital fabrication to create unique objects, whose form and function may materialise and be materialised by the consciousness of the maker. ${ }^{23}$ This external expression of needs and desires is achieved via processes of transformation between the virtual and the physical, tangling in the notion of complex embodiment. It may be possible to read such objects as responses to lived experience, and as auto/biographical materialisations accessible to people who cannot participate in conventional modes of auto/biographical production. 
While disability memoir is a well-known form of life writing, its generic conventions can serve to exclude people in various ways. The act of producing a memoir requires mastery of language, the confidence to speak, and the belief that one has a story worth telling. The conventions of memoir also imply prerequisite functions of memory and identity, assuming 'a self-identical coherence across time and space that was capable of narration'. ${ }^{24}$ Beyond the mechanics of production, the politics of disability memoir are also problematic. G. Thomas Couser (2001) identifies the 'supercrip' narratives to which most published disability memoirs conform-the life story is worthy of public attention because of the heroic achievements of the exceptional subject, who overcomes their disability to achieve success in the normatively-abled world.$^{25}$ Barrett articulates the consequences of this tendency, stating that 'auto/biographical life writing tends towards a consideration of disability primarily in terms of individual experience, perpetuating the psychologized tropes of tragedy, struggle and overcoming rather than patterns of structural oppression'. ${ }^{26}$ This emphasis, according to Barrett, creates "intense antipathy and distrust within disability studies towards "individualism". ${ }^{27}$ For these reasons, concludes Couser, 'Many lives [...] go unrepresented, uninscribed because of disability'. ${ }^{28}$

Our project wanted to test the notion that digital fabrication could do auto/biographical work. If so, could it offer ways into inclusive auto/ biographical practices that circumvent the traditional prerequisites of literary production? Extending Bruś' argument for photographic selfies, we sought to create a digital fabrication process which 'offered transforming resources for those who felt excluded from a culture of texts'. ${ }^{29}$

The ability to materialise the experiences of those who inhabit disabled positions implies political possibilities. As Charles Eisenstein (cited by Disability Rights UK), points out:

one of the more subtly political things that you can do is to make the disabled visible as full human beings, and to tell your story. What is it like to be disabled? Because that is actually very inconvenient if you are a policy-maker and you can't just write off the disabled through some set of statistics. ${ }^{30}$

The potential of digital fabrication processes to enable people to 'tell their story' in concrete (and therefore difficult to overlook) modes, is one of the findings that emerged from the 'In the Making' project. If we are on the cusp of a digital fabrication revolution, then disabled people might find ways to deploy its disruptive energy in the service of making themselves visible in the normatively-abled world, revealing their experiences on their own terms. 
The 'In the Making' project set out to explore how that might work in practice. The shift from theorising to doing, however, is where visions of digital utopia hit the first barrier. A widely-acknowledged problem with 3D printers is a general failure to use the technology in meaningfully innovative ways. As Gareth Branwyn of Make Magazine puts it, 'A lot of what we still see coming out of 3D printers are trinkets, toys (that kids won't likely play with), and joke items. ${ }^{31}$ The nub of the issue is in creative thinking. To return to Gershenfeld's phrase, generally people have difficulty thinking 'out of the box' before they get anywhere near the stage of making a new box. Digital fabrication expert David Armson describes his experiences of teaching novice makers how to use the technology. Learners engage enthusiastically until they reach the point of generating their own designs, but "when we hand it over to the individual, people just step away, because that idea of saying "make whatever you want" is quite a frightening thing. ${ }^{32}$ Such issues are particularly acute for disabled makers. One of the key challenges that emerged in the project was tackling decades of diminishment and negative attitudes which affected our co-constructors' confidence.

'In the Making' collaborated with people in Greater Manchester, a region which is often identified as containing some of the most deprived areas in the UK. ${ }^{33}$ Our co-constructors' status as disabled people compounded these existing challenges since 'Throughout the West, disabled people are significantly disadvantaged and ostracized whether one evaluates well-being by labour market participation rates, education levels, or rates of poverty'. ${ }^{34}$ In these community settings, which amplified general economic and social deprivation through the challenges faced by disabled people, a common phrase was: 'I'm just not creative'. It is almost an echo of William Blake's concept of 'mind forg'd manacles, ${ }^{35}$ in which the poet, according to David Gross, identifies self-limiting thoughts as 'a powerful cultural force'. ${ }^{36}$ Indeed, David Armson makes a similar observation about the experience of working with novice makers in the Northwest of England when he notes that: 'We do get a lot of users limiting themselves'. ${ }^{37}$

Rather than locating the problem in the disabled person's attitude towards themselves and their own abilities, it is important to understand where these deep-seated and pernicious constraints originate. As Thomas R. Bates affirms 'man [sic] is not ruled by force alone but also by ideas'. ${ }^{38}$ Where are these self-perceptions of failure and incompetence generated? The answer lies in hegemonic social narratives. Emily Russell reminds us that 'narrative has always been a central feature in constructing the public concept of disability'. ${ }^{39}$ It is not difficult to see how our project participants' self-perceptions had been negatively affected by prevalent media 
narratives of disabled people as a drain on public resources. In a recent study, Emma Briant and her co-researchers found a significant increase in negative coverage of disability in UK newspapers, with 'some articles even blaming the recession itself on incapacity benefit claimants. ${ }^{40}$

As Briant's study demonstrates, stories are powerful. They can shape identity, the self and how we relate to others. Charles Weingartner, reflecting once more upon William Blake's 'mind forg'd manacles', asserts that: 'A shift in metaphors can produce a dramatic shift in the options and choices we perceive, conceive and then act on. ${ }^{41}$ Digital fabrication offers strong resonances with the process of re-making perceptions of self and other, and the potential of metaphor to effect material change. Tracing the lineage of the verb 'to fabricate', we find that its Latin roots share common ancestry with making, inventing, crafting tales and telling stories. ${ }^{42}$ In a delicious and inadvertent parallel with digital fabrication processes, Vocabulary.com offers this usage of the word fabrication: 'to refer to the act of coming up with a story out of thin air ${ }^{\prime}{ }^{43}$ Digital fabrication can conjure almost anything out of thin air, including objects which carry the stories of their making, and even the text of stories themselves. Teresa Bruś offers a further resonance with the $3 \mathrm{D}$ selfie, pointing out that 'the conceptualisation of the face as making, as acting is rendered in the noun "face", and the verb "to face", both derived from the Latin facere meaning to do, and to make' (93). ${ }^{44}$ Just like the process it represents, the word 'fabrication' carries multiple meanings, of creating and of story-telling, of performing, facing, making things and making things up, one always present in the others, destabilising in unavoidable and often unconscious wordplay.

Such a process troubles any distinction between an idea and its physical manifestations, 'unsettling the ground of both poles (imagination/ reality) ${ }^{45}$ The continual interplay between language and world, thought and object in which any account of digital fabrication inevitably tangles demonstrates its subversive and disruptive potential. This constant shifting and refusal to settle could be read in Petra Kuppers' terms as 'leakage' where 'Time and space, living body and sedimented knowledge, semiotics and phenomenology start to leak into one another, start to overwrite one another, and begin to move' ${ }^{46}$ In the case of $3 \mathrm{D}$ printers, this movement can be witnessed physically as the print head performs its intricate act of materialisation, weaving and jolting around the print bed, employing time and space to transform thought into matter. Such leakage challenges hegemonic narratives, destabilising established perceptions of self and other as it explodes the traditional binaries of real and imagined, physical and mental, external and internal. Indeed, digital fabrication seems to challenge simultaneously the trilogy that Emily Russell identifies as the 
'...homology of physical, social and textual bodies' which constitute 'the terrain for constructing social narratives of disabled citizenship. ${ }^{47}$

The task of the 'Fabulous Fab Lab', therefore, is to attend to fabrication in all its meanings, with a view to re-making social narratives of disability via the making of personally significant objects. In keeping with the process of literal/metaphorical shifting, the creative facilitation begins with language, co-constructing opportunities to locate narratives with 'a counter-hegemonic potential to subvert or transform society' and in so doing to enable 'voices traditionally ignored to speak out'. ${ }^{48}$ What follows is a detailed account of how the 'In the Making' project attempted this narrative work, borrowing procedures from experimental creative writing practices to unlock the counter-hegemonic potential of 3D printing.

\section{BREAKING THE MANACLES}

The phrase 'mind forg'd manacles' resonates productively with the literal/metaphorical qualities of digital fabrication. A forge of the mind is an evocative way of describing a 3D printer. Once supplied with a virtual design in the form of digital code, it can materialise a physical version via the application of heat and moving metal. Our project hypothesised that, with the right support and facilitation, people could find ways to "mind forge' a key to unlock the hegemonic manacles of self-limiting thought. The manacles may be made in the mind, and sustained in many minds, but their influence in the physical world is a tangible restriction in the lives of disabled people. In keeping with the concept of complex embodiment, the key to unlocking the manacles may originate in the mind, in 'thinking out of the box'. In challenging established modes of thought and hegemonic narratives, unlocking the conceptual manacles will have material effects in that maker's external reality, in a reciprocal 'economy between social representations and the body' ${ }^{4}$

The first step in this process is to create a safe and nurturing atmosphere in which perceptions of risk and failure are re-positioned as part of a playful process in which our co-constructors could 'mess about' without consequence. A communal, preliminary act of making tea and sharing biscuits, for example, helped to create a group identity. Apparent small-talk, eliciting the stories of people's journeys to the venue, or their reasons for being there, initiated creative sharing and introduced storytelling as a core activity. 'Emergent creativity', where the intention or nature of the activity is not pre-announced, can be an effective way of getting around initial anxieties and pre-conceptions. Such activities may involve elements of meditation, visualisation and relaxation. The effects of such activities are intended to shift the group dynamic into a more 
creative and receptive state, engaging imagination, daydreaming, and transcending the constraints of the everyday.

To function effectively in a late capitalist society, we are schooled to be logical, rational and reasonable. Accessing education, welfare or health services requires our critical faculties to be strongly developed, perhaps to the point where they allow the speculative and the imaginative little room to exist. ${ }^{50}$ Creating a space in which people are freed, temporarily, from the constraints of conventional logic, reason and sense is therefore necessary if the new ideas and imaginative responses required for thinking out of the box are to be accessed. We hypothesised that poetic practices may be helpful here. Kazim Ali writes vividly about the struggle to get out of the box and how we might do so: 'we actually need a new brain, new shapes for thought. We've always already done this in poetry'. ${ }^{51}$ To this end our project collaborated with Community Interest Company ARTHUR+MARTHA to assist in the design and facilitation of some sessions. ${ }^{52}$ Lois Blackburn, visual artist, and Philip Davenport, experimental poet, are highly experienced in working with excluded groups, and they are all too familiar with the internalised narrative of 'I can't'. Davenport draws on his knowledge of experimental poetry to devise strategies capable of unlocking the manacles:

- $\quad$ open-mindedness about what creative activities are or can be;

- $\quad$ simplification via precise constraints;

- clear and limited choices;

- $\quad$ systematic application;

- $\quad$ building through reiteration of small steps;

- not announcing 'the creation' until it exists.

These strategies for getting out of the box build on experimental approaches to poetry which challenge traditional ideas about what poetry 'should be'. The endeavour to produce a poem may be understood as 'imaginative labor seeking to give form and meaning to experience'. ${ }^{53}$ When couched in these terms, experimental poetic practices seem supportive of our ambition to materialise lived experiences of disability via the products of $3 \mathrm{D}$ printing.

Davenport creates poetry with people by asking them simple questions about their experiences and feelings. For example, following some warm-up exercises (typically summarised earlier), participants are asked to respond to this question: what makes you feel free? Participants are invited, where possible, to speak their answer. Support workers act as interpreters for those who need it. The question is answered in turn by each person around the table who wishes to do so. Silence is taken as an equally valid response, which Davenport records as a gap as he writes down each participant's answers. 
A second question is then posed: what makes you feel trapped? Again, responses are elicited and recorded. Two more rounds and a collective poem has been produced. As well as giving detailed insights into the realities and concerns of disabled people, the value of this exercise and its output is that when Davenport reads back the collected answers to the group, a work of literary merit is recognised as having been brought into existence by the collective endeavour. People are surprised and pleased that they have created something of lasting cultural value.

The procedure may be repeated in variation, so that each person records their individual answers, which, when arranged in sequence, form short poems drawing on minimalist styles such as Haiku. Different questions elicit different poems:

\section{My meditation \\ Is drifting off and dreaming \\ Boundaries of time.}

Scrolling coloured light

Boundaries are limitless

I squeal like a child ${ }^{54}$

In these two poems, we see novice poets producing formally accurate and emotionally engaging Haiku. If we had announced, 'today we are going to write technically demanding Japanese poetry', many workshop participants may have reacted anxiously and talked themselves into failure before the task was even begun. Davenport's strategy of breaking the process down into discrete incremental activities removes the pressure on the self to 'be creative': the poem is made before the maker realises what they have achieved. As well as being a useful training exercise for the principles of 3D design processes, such 'emergent creativity' is an effective strategy for bypassing hegemonic narratives of lack and limitation. The writers of these two Haiku both find ways of exceeding boundaries in their respective texts. Dreaming and child-like exuberance circumvent limitations. Meditation, drifting, and squealing counter the rational, logical behaviours which can prevent us from getting 'out of the box'. The distinctly oneiric states evoked by both poems speak to the composing processes of creative writers when they literally begin to write a new story. Damon Knight, for example, describes the difficulty of articulating this encounter with the part of ourselves that generates new ideas:

'Unconscious' is a lousy term, by the way-it isn't unconscious, it just has trouble communicating. 'The silent mind' would be better, maybe, or 'the 
tongue-tied mind', but I prefer to call it 'Fred'. Fred is responsible for the images, the symbolism, the cloudy shapes of stories... ${ }^{55}$

As Knight's account attests, this effort to access the place where new stories originate is challenging for established practitioners. One can only imagine the difficulty in approaching this state of mind for those inhabiting marginalised and diminished social positions. And yet Davenport's incremental technique demonstrates the effectiveness of 'emergent creativity' in bringing novice makers to the territory where it is possible to begin to think one's way out of the box.

Progressing from process to product, one route to printing was to use text itself as a direct source of material. The project facilitators developed a process for printing 3D text, which could be purposed as wearable (a badge or a cuff), or as a wall-plaque, paperweight, or ruler. From the poetic material, participants selected text, typed or dictated the words into the software, made aesthetic decisions about design, color and font, and then wore their own words in a fascinating performance of embodied auto/biography.

As Figure 8 shows, the handwritten script was too fine for our printers to negotiate, so a facilitator helped the participant to import his text into design software:

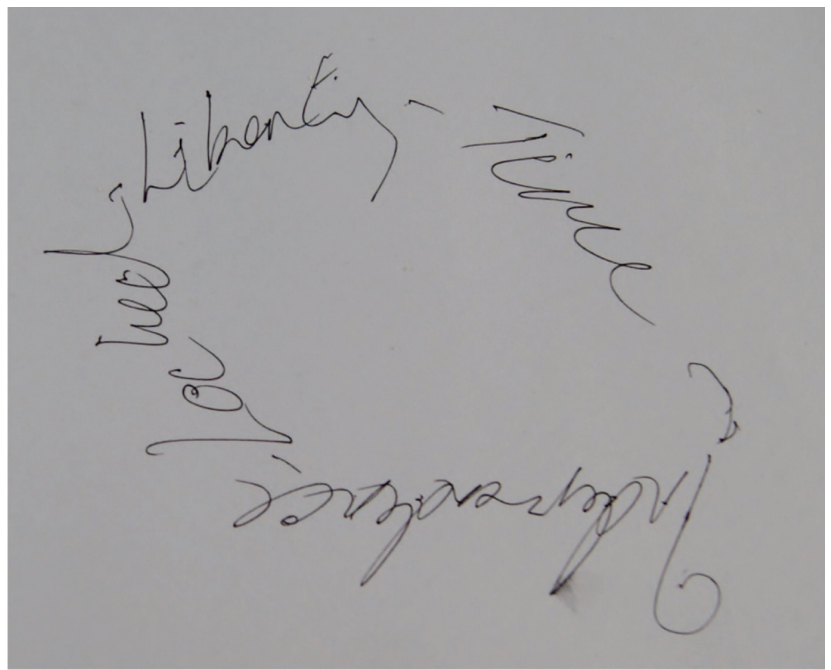

Figure 8 . This maker's physical condition caused difficulty in writing, but also produced a beautiful, flowing script, which our artist facilitator felt had great potential aesthetically. 
Figures 9, 10 and 11 illustrate how the project's technical and creative facilitators became adept at using these poetic routines to generate personally meaningful, wearable text with our participants. For some, the required brevity of text selected for printing opened a creative space. Such modes of expression circumvent the memoir's traditional requirements of 'sense-making'. Carefully selected text can function like the tip of an iceberg, carrying depths of experience and association beneath it, without needing the connective tissue of how and why. Project participants

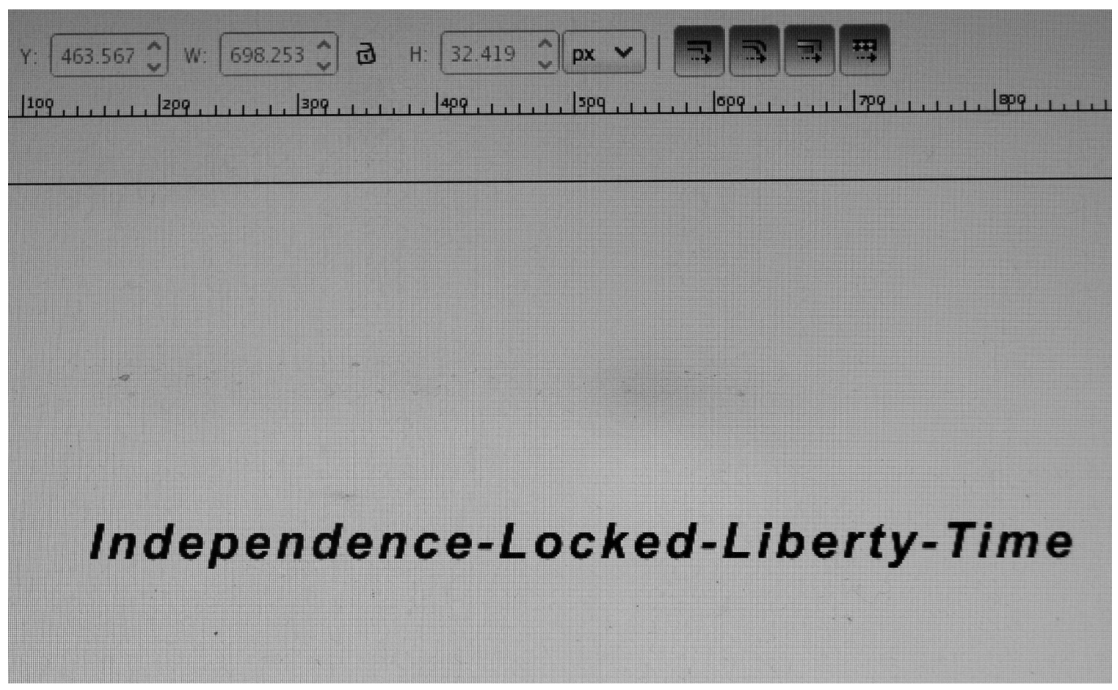

Figure 9. Our technical facilitators developed a simple method for typing text into Inkscape (freely available open source software). Inkscape allows variation in type face, size and effects such as bold or italic. Most participants were able to select and enter their text themselves. Facilitators then exported the file to the 3D printer software, which was able to read the text as relief or embossed lettering.

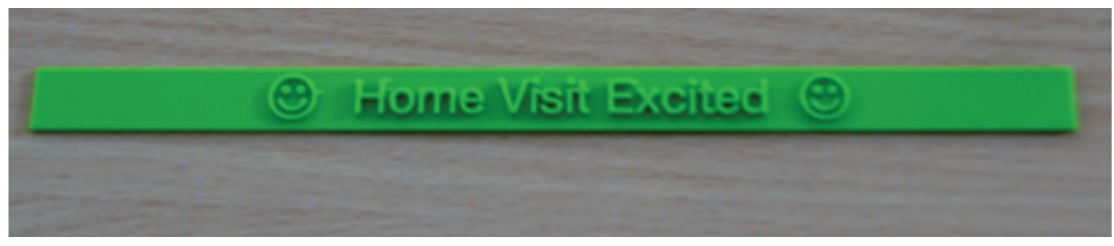

Figure 10. Text and simple graphics produced via the Inkscape technique. Participants selected the color of the print filament. 


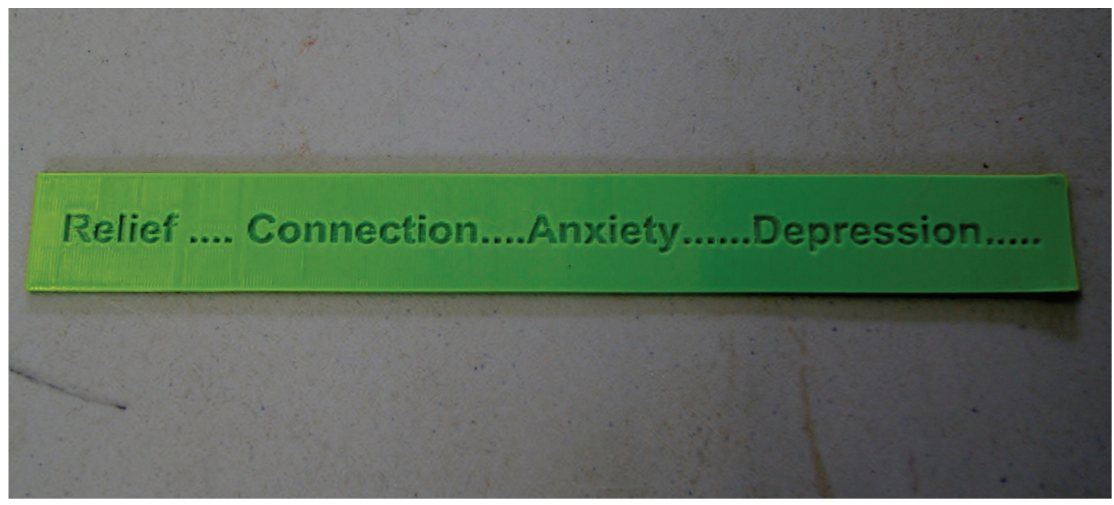

Figure 11. This maker chose to depress the text to echo the experience of depression. They chose to purpose this print as a ruler but, if submerged in hot water, the PLA filament could be bent to form a wearable cuff. Facilitators worked carefully with participants who chose to make a cuff, ensuring that the water was not too hot, nor the cuff too tight.

appeared pleased and enthusiastic about the text-objects that they had created, showing them eagerly to friends, family and supporters, engaging in newly invigorated self-presentations.

Progressing from the production of brief, meaningful concrete text, the final stage of our project supported makers to explore ways of moving into material modes of expression which played with the idea of 'taking metaphors literally'. Figure 12 offers one such example.

For this maker, the curve of the leaf inspired the word 'harmonic', and the arrangement of letters to replicate the pleasing curve of the natural structure. The green plaque shows the result of an experiment where the leaf was 3D scanned and combined with the relief lettering to create a threedimensional synthesis of a complex organic form, a poetic response, and digital fabrication. This resulted in a prototype plaque which could be developed as wall art, a 'stamp' to be used with ink, or even a three-dimensional greetings card. It could also form a badge or a necklace with the addition of a chain or a pin. Potentially, this making could lead to entrepreneurial activity, directly challenging narratives about disabled people being the passive recipients of state resources. While other art forms also offer such possibilities, few can rival 3D printing's ability to sustain a novice practitioner's explorations in which idea and text are concretised and placed in relationships with 'real world' objects which are in turn rendered metaphorical.

As the 'In the Making' project found, poetic process is not just a way into thinking outside the box, but a direct route to digital fabrication practices, which may themselves be read as a kind of poetic language. In Ali's terms, poetic language offers us opportunities 'for increasing 


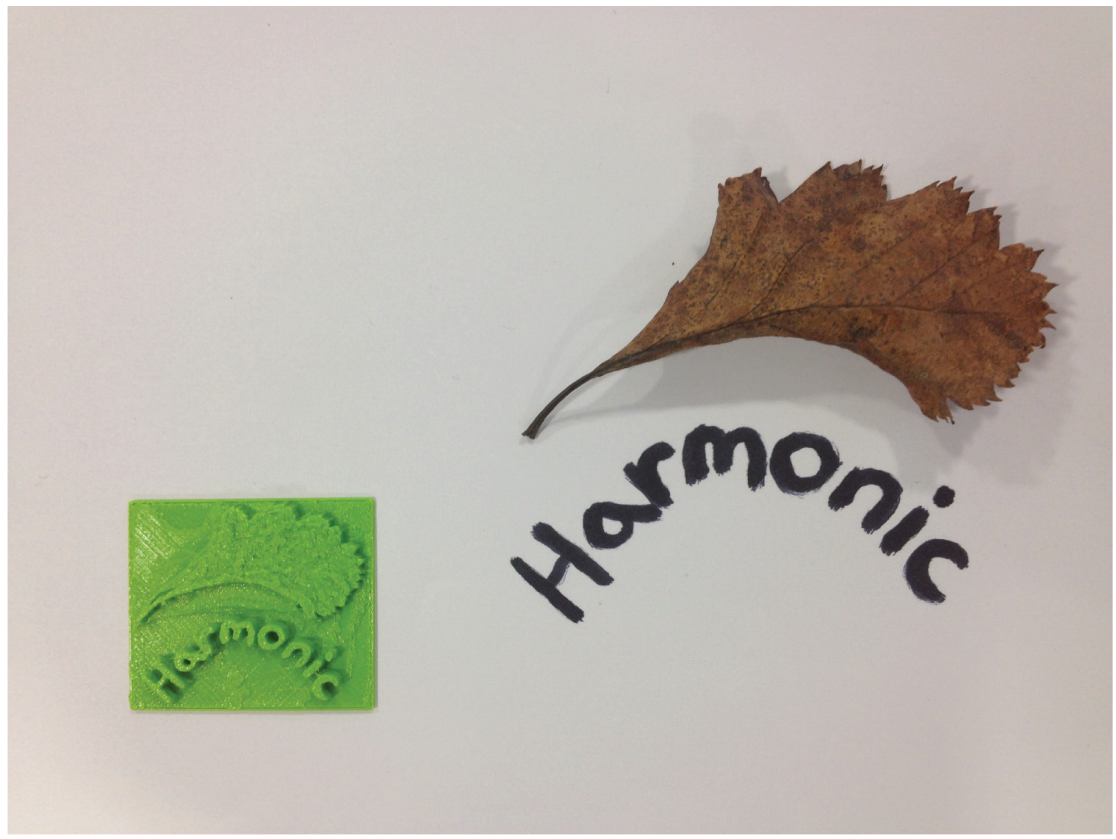

Figure 12. Autumn leaf, poetic response and combined 3D print. Photo copyright Arthur+Martha.

human perception'. ${ }^{56}$ What I hope to have suggested in this reflective essay is that digital fabrication may, in the materialisation of hitherto intangible aspects of disability, evoke 'a glimpse of a life being lived and communicated ... beyond or without the resources of what we usually recognize as ... auto/biography'. ${ }^{57}$

\section{ACKNOWLEDGEMENTS}

Thanks to the Arts and Humanities Research Council and everyone else who gave so freely of their time and expertise. Finally, grateful thanks to our collaborators, without whom we would have achieved nothing.

\section{WORKS CITED}

Ali, Kazim. "Genre-Queer: Notes Against Generic Binaries.” Eds. Margot Singer and Nicole

Walker. Bending Genre: Essays on Creative Nonfiction. London: Bloomsbury, 2013. 27-38. Armson, David. Personal Interview. 29 April 2015. 
Bailey, Rowan. "Ways of Reading 'Gestured'." Brass Art: Gestured 2017. https://library.chethams.com/wp-content/uploads/sites/3/2017/12/Gestured_Essay_R.Bailey-2.pdf. Date accessed: 16 December 2018.

Barrett, Timothy. "De-individualising Auto/biography: A Reconsideration of the Role of Auto/biographical Life Writing within Disability Studies.” Disability and Society 29.10 (2014): 1569-1582.

Bates, Thomas R. "Gramsci and the Theory of Hegemony." Journal of the History of Ideas 36.2 (April-June 1975): 351-366. http://www.jstor.org/stable/2708933. Date accessed: 3 July 2018.

Ben-Moshe, Liat. "'The Institution Yet to Come': Analyzing Incarceration Through a Disability Lens.” Ed. Lennard J. Davis. The Disability Studies Reader, 4th edition. London: Routledge, 2013. 132-143.

Branwyn, Gareth. "Over 100 3D Printing Projects for Your Home." Make Magazine 19 November 2015. https://makezine.com/2015/11/19/over-100-3d-printing-projects-foryour-home/. Date accessed: 27 November 2017.

Briant, Emma, Nick Watson, Greg Philo, and Inclusion London. "Bad News for Disabled People: How the Newspapers are Reporting Disability." Strathclyde Centre for Disability Research and Glasgow Media Unit, The University of Glasgow, 18 November 2011. http://eprints.gla.ac.uk/57499/. Accessed 27 November 2017.

Bruś, Teresa. "Recent Zones of Portraiture: The Selfie." European Journal of Life Writing 6 (2017): 87-100. https://doi.org/10.5463/ejlw.6.227. Date accessed: 30 December 2018.

Causey, Matthew. Theatre and Performance in Digital Culture: From Simulation to Embeddedness. London: Routledge, 2006.

Childers, Joseph and Gary Hentzi, eds. The Columbia Dictionary of Modern Literary and Cultural Criticism. New York: Columbia University Press, 1995.

Department for Communities and Local Government. "The English Indices of Deprivation.” 2015. Www.gov.uk/government/uploads/system/uploads/attachment_data/ file/465791/English_Indices_of_Deprivation_2015_-_Statistical_Release.pdf. Date accessed: 10 May 2017.

Disability Rights UK. “The 'Affordable Papers': Contributions to an Economy That Includes Disabled People.” 2016. www.disabilityrightsuk.org/sites/default/files/pdf/AffordablePapers.pdf. Date accessed: 1 May 2018.

Freeman, Mark. "Culture, narrative, and the Poetic Construction of Selfhood." Journal of Constructivist Psychology 12.2 (1999): 99-116.

Gershenfeld, Neil. Fab: The Coming Revolution on Your Desktop-From Personal Computers to Personal Fabrication. New York: Basic Books, 2005.

Gershenfeld, Neil. "How to Make Almost Anything: The Digital Fabrication Revolution." Foreign Affairs 91.6 (2012): 43-57. cba.mit.edu/docs/papers/12.09.FA.pdf. Date accessed: 1 May 2018.

Gilpin, Lyndsey. "The Dark Side of 3D Printing: 10 Things to Watch.” Tech Republic 2014. www.techrepublic.com/article/the-dark-side-of-3d-printing-10-things-to-watch/. Date accessed: 1 May 2018.

Gross, David. "'Mind-Forg'd Manacles': Hegemony and Counter-Hegemony in Blake.” The Eighteenth Century 27.1 (Winter 1986): 3-25. http://www.jstor.org/stable/41467368. Date accessed: 3 July 2018.

Johnson, Christopher. "Ambient Technologies, Uncanny Signs." Oxford Literary Review 21 Technologies of the Sign (1999): 117-134.

Kneebone, Roger. "When I say ... Reciprocal Illumination.” Medical Education 49 (2015): 861-862. doi:10.1111/medu.12743. Date accessed: 3 July 2018.

Knight, Damon. Creating Short Fiction. New York: St Martins Griffin, 1997.

Kuppers, Petra. Disability and Contemporary Performance: Bodies on the Edge. London: Routledge, 2003. 
Lau, Manfred, Jun Mitani, and Takeo Igarashi. "Digital Fabrication.” Computer 45.12 (2012): $76-79$.

Malhotra, Ravi, and Morgan Rowe. Exploring Disability Identity and Disability Rights Through Narratives: Finding a Voice of Their Own. London: Routledge, 2013.

Nelson, Bryan. "Scientists closer to creating a 'Star Trek'-style replicator." Mother Nature Network 2015. https://www.mnn.com/green-tech/research-innovations/stories/scientists-closer-creating-star-trek-style-replicator. Date accessed: 1 May 2018.

Royle, Nicholas. The Uncanny. Manchester and New York: Manchester University Press, 2003.

Russell, Emily. Reading Embodied Citizenship: Disability, Narrative, and the Body Politic. New Brunswick: Rutgers University Press, 2011.

Siebers, Tobin. "Disability and the Theory of Complex Embodiment-For Identity Politics in a New Register." Ed. Lennard J. Davis. The Disability Studies Reader, 4th edition. London: Taylor and Francis, 2013. 278-297.

Walter-Herrmann, Julia, and Corinne Büching. "Notes on Fab Labs." Eds. Julia Walter-Herrmann and Corinne Büching. FabLab: Of Machines, Makers and Inventors. Bielefeld: Transcript Verlag, 2013. 9-26.

Weingartner, Charles. "MIND FORG'D MANACLES..." Educational Studies 8.1 (1977): 21-27. doi.org/10.1207/s15326993es0801_2. Date accessed: 3 July 2018.

\section{ABOUT THE AUTHOR}

Ursula Hurley is Senior Lecturer in English and Creative Writing at the University of Salford. She works critically and creatively in experimental and innovative auto/biographical practices, ranging from historical, fictionalized narratives to digitally fabricated artifacts. She is in the process of completing a book-length project on disability and digital fabrication. Email: U.K.Hurley@salford.ac.uk.

\section{NOTES}

1 Walter-Herrmann, Julia and Corinne Büching, 'Notes on Fab Labs.' In: Julia Walter-Herrmann and Corinne Büching (eds.), FabLab: of Machines, Makers and Inventors. Bielefeld: Transcript Verlag, 2013, 9-26. (10)

2 Nelson, Bryan. 'Scientists closer to creating a "Star Trek"-style replicator.' Mother Nature Network, 2015, https://www.mnn.com/green-tech/research-innovations/stories/scientists-closer-creating-star-trek-style-replicator. Date accessed: 1 May 2018.

3 Johnson, Christopher. 'Ambient Technologies, Uncanny Signs.' Oxford Literary Review 21: Technologies of the Sign (1999), 117-134. (132n2)

4 I follow the advice of Disability Rights UK in using the term 'disabled people'. For a critical account of how such terminology may contribute to the reclaiming of the term 'disabled', please see Wexler, Alice and John Derby. 'Art in Institutions: The Emergence of (Disabled) Outsiders.' Studies in Art Education: A Journal of Issues and Research 56: 2 (2015), 127-141.

5 Neil Gershenfeld established a standard inventory of digital fabrication equipment for maker spaces, or Fab Labs, at the Massachusetts Institute for Technology's Center for Bits and Atoms. The Fab Lab movement is now a global network: fab.cba.mit.edu/about/charter/.

6 Gershenfeld, Neil. Fab: The Coming Revolution on Your Desktop-From Personal Computers to Personal Fabrication. New York: Basic Books, 2005. (24) 
7 Gilpin, Lyndsey. 'The dark side of 3D printing: 10 things to watch.' Tech Republic, 2014, www.techrepublic.com/article/the-dark-side-of-3d-printing-10-things-to-watch/. Date accessed: 1 May 2018.

8 Lau, Manfred, Jun Mitani and Takeo Igarashi. 'Digital Fabrication.' Computer 45:12 (2012), 76-79. (76)

9 Causey, Matthew. Theatre and Performance in Digital Culture: From Simulation to Embeddedness. London: Routledge, 2006. (16)

10 Ibidem.

11 Kneebone, Roger. 'When I say ... reciprocal illumination.' Medical Education 49 (2015), 861-862 doi:10.1111/medu.12743. Date accessed: 3 July 2018. (861)

12 Bruś, Teresa. 'Recent Zones of Portraiture: The Selfie.' European Journal of Life Writing 6 (2017), 87-100. https://doi.org/10.5463/ejlw.6.227. Date accessed: 30 December 2018. (88)

13 Ibidem.

14 Idem, page 87.

15 Bailey, Rowan. 'Ways of Reading "Gestured”.' Brass Art: Gestured, 2017, https://library. chethams.com/wp-content/uploads/sites/3/2017/12/Gestured_Essay_R.Bailey-2.pdf. Date accessed: 16 December 2018.

16 Ibidem.

17 Ben-Moshe, Liat. "The Institution Yet to Come”: Analyzing Incarceration Through a Disability Lens.' In: Lennard J. Davis (ed.), The Disability Studies Reader 4th edition. London: Routledge, 2013, 132-143. (133)

18 Ibidem.

19 Ibidem.

20 Johnson, Christopher. 1999.

21 Gershenfeld, Neil. The Coming Revolution. 2005. (24)

22 Barrett, Timothy. 'De-individualising Auto/biography: A Reconsideration of the Role of Auto/biographical Life Writing within Disability Studies.' Disability and Society 29:10 (2014), 1569-1582. (1575)

23 Gershenfeld, Neil. 'How to Make Almost Anything: The Digital Fabrication Revolution.' Foreign Affairs 91:6 (2012), 43-57 http://cba.mit.edu/docs/papers/12.09.FA.pdf. Date accessed: 3 July 2018.

24 Barrett, Timothy. 2014. (1571)

25 Couser, G. Thomas. 'Conflicting Paradigms: The Rhetorics of Disability Memoir.' In: James C. Wilson and Cynthia Lewiecki-Wilson (eds.), Embodied Rhetorics: Disability in Language and Culture. Carbondale: Southern Illinois University Press, 2001, 78-91.

26 Barrett, Timothy. 2014. (1571)

27 Ibidem.

28 Couser, G. Thomas. 2001. (88)

29 Bruś, Teresa. 2017. (90)

30 Disability Rights UK. 'The "Affordable Papers": Contributions to an Economy That Includes Disabled People.' 2016, https://www.disabilityrightsuk.org/sites/default/files/ pdf/AffordablePapers.pdf. Date accessed: 3 July 2018. (14)

31 Branwyn, Gareth. 'Over 100 3D Printing Projects for Your Home.' Make Magazine, 19 November 2015, https://makezine.com/2015/11/19/over-100-3d-printing-projects-foryour-home/. Date accessed: 27 November 2017.

32 Armson, David. Personal interview. 29 April 2015.

33 Department for Communities and Local Government. 'The English Indices of Deprivation.' 2015, https://www.gov.uk/government/uploads/system/uploads/attachment_ data/file/465791/English_Indices_of_Deprivation_2015_-_Statistical_Release.pdf. Date accessed: 10 May 2017. 
34 Malhotra, Ravi and Morgan Rowe. Exploring Disability Identity and Disability Rights Through Narratives: Finding a Voice of Their Own. London: Routledge, 2013. (1)

35 The poem 'London' by William Blake was written c.1790: 'In every cry of every Man, / In every Infants cry of fear, / In every voice: in every ban, / The mind-forg'd manacles I hear' Full text available at: /www.poetryfoundation.org/poems-and-poets/poems/ detail/43673. Date accessed: 3 July 2018.

36 Gross, David. 'Mind-Forg'd Manacles": Hegemony and Counter-Hegemony in Blake.' The Eighteenth Century 27:1 (Winter 1986), 3-25 http://www.jstor.org/stable/41467368. Date accessed: 3 July 2018. (3)

37 Armson, David. Personal interview. 29 April 2015.

38 Bates, Thomas R. 'Gramsci and the Theory of Hegemony.' Journal of the History of Ideas 36: 2 (April-June 1975), 351-366 http://www.jstor.org/stable/2708933. Date accessed: 3 July 2018. (351)

39 Russell, Emily. Reading Embodied Citizenship: Disability, Narrative, and the Body Politic. New Brunswick: Rutgers University Press, 2011. (3)

40 Briant, Emma, Nick Watson, Greg Philo and Inclusion London. 'Bad News for Disabled People: How the Newspapers are Reporting Disability.' Strathclyde Centre for Disability Research and Glasgow Media Unit, The University of Glasgow, 18 November 2011, http://eprints.gla.ac.uk/57499/. Accessed 27 November 2017. (9)

41 Weingartner, Charles. 'MIND FORG'D MANACLES...' Educational Studies 8:1 (1977), 21-27 doi.org/10.1207/s15326993es0801_2. Date accessed: 3 July 2018. (21)

42 Collins English Dictionary, 2012 Digital Edition.

43 Vocabulary.com.

44 Bruś, Teresa. 2017. (93)

45 Royle, Nicholas. The Uncanny. Manchester and New York: Manchester University Press, 2003. (15)

46 Kuppers, Petra. Disability and Contemporary Performance: Bodies on the Edge. London: Routledge, 2003. (19-20)

47 Russell, Emily. 2011. (3)

48 Malhotra, Ravi and Morgan Rowe. 2013. (8)

49 Siebers, Tobin. 'Disability and the Theory of Complex Embodiment-For Identity Politics in a New Register.' In: Lennard J. Davis (ed.) The Disability Studies Reader 4th edition. London: Taylor and Francis, 2013, 278-297. (290)

50 Childers, Joseph and Gary Hentzi (eds.) The Columbia Dictionary of Modern Literary and Cultural Criticism. New York: Columbia University Press, 1995. (103)

51 Ali, Kazim. 'Genre-Queer: Notes Against Generic Binaries.' In: Margot Singer and Nicole Walker (eds.), Bending Genre: Essays on Creative Nonfiction. London: Bloomsbury, 2013, 27-38. (35)

52 More information about the work of Arthur+Martha may be found here: arthur-andmartha.blogspot.co.uk/.

53 Freeman, Mark, 'Culture, Narrative, and the Poetic Construction of Selfhood.' Journal of Constructivist Psychology 12:2 (1999) 99-116. (99)

54 The 'In the Making' project has ethical approval from The University of Salford. Each participant co-constructed a personalised permissions document, detailing, according to their expressed preferences, how much of their data the researchers could use and in what ways. All of the materials appearing in this essay were generated by people who have given permission for their work to be used in academic publications. However, individuals have not been identified due to the sensitive nature of the material.

55 Knight, Damon, Creating Short Fiction. New York: St Martins Griffin, 1997. (24)

56 Ali, Kazim. 2013. (38)

57 Barrett, Timothy. 2014. (1575) 